\title{
Miscegenation and heterogeneity of a Brazilian sample of schizophrenics: are they reason enough?
}

\author{
Miscigenação e heterogeneidade de uma amostra brasileira de esquizofrênicos: motivo \\ suficiente?
}

Alexandre Shoji

\author{
Departamento de Medicina Nuclear, \\ Faculdade de Medicina, \\ Universidade de São Paulo, Sao \\ Paulo SP, Brazil.

\section{Correspondence:} \\ Alexandre Shoji; Rua Sergipe, \\ 441 - sala 72; 01243-001 \\ São Paulo SP, Brasil; \\ E-mail: alexandre.shoji@gmail.com \\ Conflict of interest: \\ There is no conflict of interest to \\ declare. \\ Received 14 June 2014 \\ Accepted 30 June 2014
}

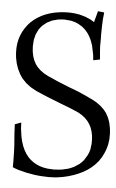

chizophrenia is a very complex disease that affects millions of patients worldwide, with no restriction of gender, ethnicity or socioeconomic levels. The chronicity and the side effects caused by the medications; antipsychotics, antidepressants, anticonvulsants; lead to a heavy burden and loss of quality of life to the patient and all those around him. The complexity of the treatment is not a matter of chance. The physiopathology is poorly understood, there is no specific biomarker and the diagnosis is still made by descriptive symptoms in an almost checklist fashion. Epidemiological studies have already shown the intricate entanglement between genetical and environmental factors in the development of schizophrenia and psychotic disorders. The heritability of $80 \%$ but a concordance of only $40 \%$ in identical twins is only a hint of the genetic complexity involved in the development of the disorder ${ }^{1}$. Following the most prevalent theory of the dopaminergic transmission as one of the causes for psychotic symptoms, geneticists examined thoroughly the genes involved in this process. One of these candidate sequences is the NTAD cluster, comprised by the NCAM1, TCC12, ANKK1 and DRD2 genes².

In an evolutionary point of view it is not a coincidence that these genes are grouped together. The NCAM1 gene encodes a protein involved in the cell to cell and cell to matrix interactions during development of the central nervous system. The TCC12 encodes a protein which function is still not clear, probably involved in the dopaminergic transmission via the Wnt signaling pathway. The ANKK1 encodes a protein closely involved in the signal transduction pathway specially the DRD2, the gene responsible for the D2 dopamine subtype receptor. The Taq1A polymorphism, located in the ANKK1 exon, was previously correlated to addiction, antisocial behavior, eating disorder, attention deficit hyperactivity disorder, smoking behavior, major depression as well bipolar disorder, showing the importance of these genes in the normal developement of the central nervous system and the genesis of diverse psychiatric disorders ${ }^{4}$.

Following this line of reasoning, Cordeiro and Vallada published in the present issue of Arquivos de Neuro-Psiquiatria a paper trying to clarify the influence of the Taq1A polymorphism in the pathogenesis of schizophrenia in a Brazilian sample ${ }^{5}$. It is indeed the first of the kind in this population and follows several other papers with the advantage of a larger sample. Parsons et al. found the same higher prevalence of A2 allele in the subjects but with only 165 controls and 119 subjects $^{6}$. This study is notable for another reason; the population studied is of Basque ancestry with very low levels of miscegenation and heterogeneity. Aslan et al. couldn't replicate the same results in a Turkish sample; the allelic frequency is completely different from the other western studies cited and no association between the A2 allele and schizophrenia was found?

These three papers are good representatives of how difficult and complex can be the interpretation of results. Heterogeneity of the studied population due to miscegenation, small samples with insufficient statistical power, stratification, or even the primary hypothesis are the causes for such discrepancy in results. It is clear now that the genes involved 
have small or no impact when taken individually and only a multiple gene approach can bear better results. The gap between gene expression and behavior is still far from being closed; genetics are one side of the bridge, identifying the genes responsible for disease are a important step and with this paper Cordeiro and Vallada clarified this point.
Perhaps it is the time to change the stratification of subjects, considering not only gender and clinical subtypes but other findings such as imaging (MRI and PET), immunological profile and response to treatment. This war has to be fought in several different fronts with all weapons that we have available.

\section{References}

1. Cardno G, Gottesman II. Twin studies of schizophrenia: from bowand-arrow concordances to star wars $\mathrm{Mx}$ and functional genomics. Am J Med Genet 2000;97:12-17.

2. Dubertret C, Bardel C, Ramoz N, et al. A genetic schizophreniasusceptibility region located between the ANKK1 and DRD2 genes. Prog Neuropsychopharmacol Biol Psychiatry 2010;34:492-499.

3. Mota NR, Araujo-Jnr EV, Paixão-Côrtes VR, Bortolini MC, Bau CHD Linking dopamine neurotransmission and neurogenesis: the evolutionary history of the NTAD (NCAM1-TTC12-ANKK1-DRD2) gene cluster. Genet Mol Biol 2012;35:912-918.

4. Ponce G, Pérez-González R, Araqüés M, et al. The ANKK1 kinase gene and psychiatric disorders. Neurotox Res 2009;16:50-59.
5. Cordeiro Q, Vallada H. Association study between the Taq1A (rs1800497) polymorphism and schizophrenia in a Brazilian sample. Arq Neuropsiquiatr 2014;72:582-586.

6. Parsons MJ, Mata I, Beperet, M et al. A dopamine D2 receptor generelated polymorphism is associated with schizophrenia in a Spanish population isolate. Psychiatr Genet 2007;17:159-163.

7. Aslan S, Karaoguz MY, Eser HY, Karaer DK, Taner E. Comparison of DRD2 rs1800497 (TaqIA) polymorphism between schizophrenic patients and healthy controls: lack of association in a Turkish sample. Int J Psychiatry Clin Pract 2010;14:257-261. 